ISSN 1112-9867

Available online at http://www.jfas.info

\title{
DATA VISUALIZATION OF TEMPORAL OZONE POLLUTION BETWEEN URBAN AND SUB-URBAN LOCATIONS IN SELANGOR MALAYSIA
}

\author{
N. Shaadan", L. N. Nazeri, M. F. M. Jalani, N. F. A. A. Rahman and R. R. Roslan \\ Center for Statistical and Decision Science, Faculty of Computer and Mathematical Sciences, \\ UniversitiTeknologi MARA, 40450 Shah Alam, Selangor, Malaysia
}

Published online: 10 November 2017

\begin{abstract}
In Malaysian environment, ground level zone has been reported as one of the most important pollutants that contribute to air quality degradation. The odourless and invisible nature of the pollutant has caused problems for individuals to realize and notice the existence of Ozone pollution in the environment. Thus, this study was conducted with the aim to assess and visualize the occurrence of potential Ozone pollution severity of two chosen locations in Selangor, Malaysia: Shah Alam (urban) and Banting (sub-urban). Data visualization analytics were employed using Ozone exceedances and Principal Component Analysis (PCA). The study results have shown an increasing pattern of Ozone pollution occurrence with several modes of distinct diurnal variations at the locations. The study also provides strong insights that Banting might experience a higher potential for Ozone pollution severity compared to Shah Alam.
\end{abstract}

Keywords: ozone pollution; air quality; data visualization; data analytics; principal component analysis.

Author Correspondence, e-mail: shahida@tmsk.uitm.edu.my

doi: http://dx.doi.org/10.4314/jfas.v9i6s.37 


\section{INTRODUCTION}

Ground level Ozone $\left(\mathrm{O}_{3}\right)$ that is also known as tropospheric $\mathrm{O}_{3}$ is a naturally occurring gas when nitrogen oxide (NOx) gases from vehicles and industrial emissions react with volatile organic compounds (VOC), which contain chemicals that evaporate easily into the air. $\mathrm{O}_{3}$ is a secondary pollutant meanwhile NOx and VOC are the precursors which are also known as primary pollutant. NOx come from human activity such as burning of coal, gasoline and oil in motor vehicles, homes, industries and power plants. Meanwhile, main source of VOC that come from human activity includes gasoline combustion, upstream oil and gas production, wood combustion and liquid fuels and solvent. VOC also come from natural source such as coniferous forest. Many studies have reported that the ground level $\mathrm{O}_{3}$ is a harmful air pollutant that is destructive to be inhaled and it harms yields, trees, and vegetation [1]. Shortterm exposure to peak levels of $\mathrm{O}_{3}$ can temporarily affect the lungs, respiratory tract, eyes and can also increase susceptibility to inhaled allergens while long-term exposure to $\mathrm{O}_{3}$ has primarily been found to reduce lung functions and has been found to be linked with a higher risk of death from respiratory causes [2]. In fact, it is estimated that by 2050 , there will be 2 millions acute mortalities in the EPPA world regions due to $\mathrm{O}_{3}$ pollution [3]. The EPPA is a computable general equilibrium model of the world economy.

In the Malaysian environment, $\mathrm{O}_{3}$ has been identified as one of the most important air pollutants other than PM10, Nitrogen Oxide (NOx), Carbon monoxide (CO) and Sulfur Dioxide $\left(\mathrm{SO}_{2}\right)$. It has been included in the computation of the country's Air Pollution Index (API). Vehicles and industrial activity have been reported to be the major contributors to $\mathrm{O}_{3}$ pollution [4]. The major industries affecting air quality are the iron and steel industry, nonferrous metal industry, nonmetallic (mineral) industry, oil and gas industry, petrochemical industry, pulp and paper, power plants and waste incineration sector [25].

Nowadays, the study on $\mathrm{O}_{3}$ pollution is growing in popularity among the Malaysian researchers. Most of the studies focus on the modeling of $\mathrm{O}_{3}$ and its precursors as well as obtaining the best distribution and time series models for prediction purposes. Urban and industrial areas are the favourite study locations. Issues on $\mathrm{O}_{3}$ status and variation are also found as the other topics of interest. Among the studies that have been conducted, in [5] has found strong seasonal atmospheric $\mathrm{O}_{3}$ concentration variations in five locations over 
Peninsular Malaysia including Bayan Lepas, Subang, Kuantan, Kota Bharu and Johor Bharu. A study by [4] has shown a distinct seasonal pattern of $\mathrm{O}_{3}$ across the Klang Valley, within the state of Selangor involving Gombak, Nilai, Klang, Petaling Jaya, Kajang, Shah Alam, TanjungMalim, Putrajaya and Cheras. The study also revealed that Shah Alam has recorded the largest number of hours exceeding the $1-\mathrm{h}-\mathrm{O}_{3}$ standard guided by the Malaysian Air Quality Guideline (MAQG) of $0.01 \mathrm{ppm} . \mathrm{O}_{3}$ exceedances in Klang valley were also found to be strongly influenced by local pollutant emission and dispersion characteristics. The findings were also supported by the publication of [6]. Among the studied areas, other than Shah Alam, Cheras also consistently showed a high frequency of noncompliance to the standards. In the case of the three major port cities such as Klang, Perai, and PasirGudang, in [7] showed that UVB was the largest contributor to $\mathrm{O}_{3}$ variation followed by temperature, relative humidity and wind speed. The exposure of the population in the three port cities to the elevated levels of $\mathrm{O}_{3}$ was found during January-May months.Another recent study by [8] also found that the concentrations of $\mathrm{O}_{3}$ recorded in Malaysian Borneo during the study period were below the standard, whereby ozone is more pronounce at industrial locations, especially in Bintulu. In addition,based on a year (2005) data, in [9] has found that, in comparison to Nilai, Shah Alam has a higher maximum $\mathrm{O}_{3}$ level, the peak occurred between 1:00 to 2:00 p.m in the afternoon. The negative relationship between $\mathrm{O}_{3}$ and NOx showed evidence of photochemical formation of $\mathrm{O}_{3}$ in Nilai and Shah Alam.

The above reviewed researches indicate that research issues on $\mathrm{O}_{3}$ variations have been considered for the Malaysian environment. However, the spatial and temporal patterns of $\mathrm{O}_{3}$ pollutionand itspotential severity are less visually assessed. In statistics point of view, visualization is critical to data analysis as visualization provides a good approach in revealing intricate structure in the data that cannot be observed in any other way. Even though the table is often being used to review data, the use of it is not sufficient since it does not allow immediate identification of patterns within the data.On the other hand, nowadays, data visualization has become popular among researchers, particularly those who deal with big data. Data visualization has the ability to synthesize large amount of data into effective graphics [10] to ease the human brain to comprehend images versus word or numbers [11]. As stated by [12],"Visualization is concerned with representing, manipulating and exploring data 
and information graphically in such a way as to gain understanding and insight into it, i.e., mapping of data to a visual form that supports human interaction in a workspace for visual sense making". Furthermore, in the context of management, data visualization can be used to quickly appraise the interactions of management actions [13] and support management decision [14].

With respect to the usefulness of data visualization that gives value to data analysis, this study is conducted. The main aim of this study is to provide valuable insight on the potential time (temporal) severity of $\mathrm{O}_{3}$ pollution that could occur between two locations in the state of Selangor in Peninsular Malaysia, namely Shah Alam and Banting. Data visualization analytics were conducted using $\mathrm{O}_{3}$ exceedances and Principal Component Analysis (PCA) based on a three-year's hourly recorded data between 2012 until 2014, which was obtained from the Department of Environment (DOE) Malaysia. By means of data visualization, the techniques could overcome the problems to increase understanding of the $\mathrm{O}_{3}$ pollution at the two locations. The information is needed as inputs for adaptation and mitigation purposes.

\section{DATA AND STUDY LOCATIONS}

Fig. 1 displays the study locations, which are Shah Alam and Banting. The locations are within the state of Selangor situated in Peninsular Malaysia. Shah Alam is the capital city of Selangor which is an urban area while Banting is in the sub-urban area, a small town located near the beaches of Morib as well as hills, forest and farms. Banting is an agricultural hub. Its main agricultural resources include oil palm plantations, poultry farms, betel leaves and it has a number of industrial areas. Both locations have consistent temperatures throughout the year with an average high temperature of $31.9^{\circ} \mathrm{C}$ and an average low temperature of $23.2{ }^{\circ} \mathrm{C}$ and warmest in the month of March. Like other parts in Malaysia, the weather at the location is normally influenced by four types of monsoon seasons: the Northeast (November-March), first transition, Southwest (June-September) and the second transition.

Data for the study analysis consist of hourly data for a three-year period from year 2012 until 2014. The data were obtained from two air quality monitoring stations: Shah Alam and Banting, which are owned by the Department of Environment (DOE), Malaysia and managed by a private company which is Alam Sekitar Malaysia Sdn. Bhd. The $\mathrm{O}_{3}$ concentration was 
measured using the Teledyne $\mathrm{O}_{3}$ analyzer model 400A UV absorption. The company practices calibration and standard to ensure good quality data collection and records.

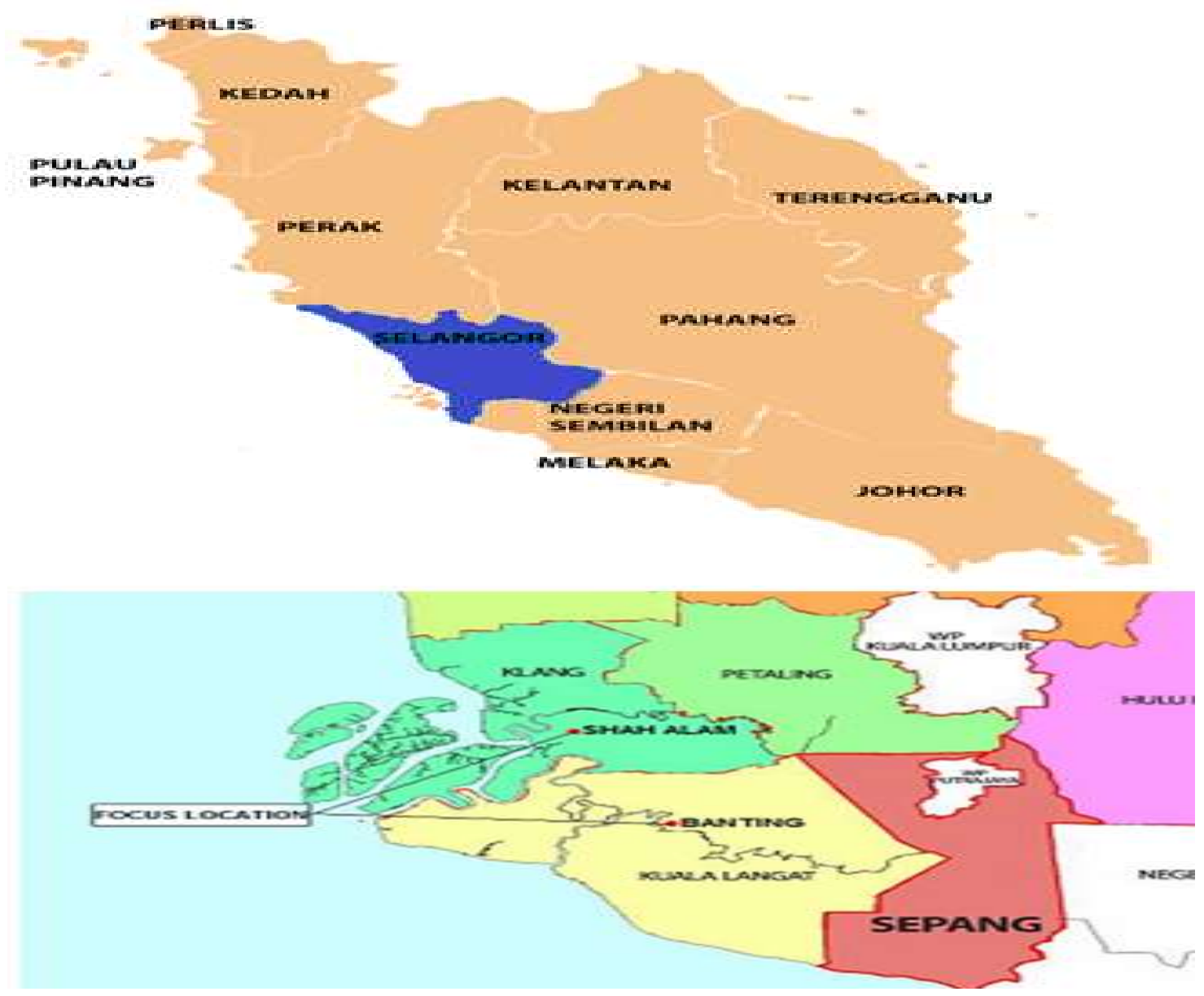

Fig.1. Map of Shah Alam and Banting, within the state of Selangor in Peninsular Malaysia

\section{DATA ANALYSIS AND TECHNIQUES}

Several data analyses were conducted to achieve the study objectives. The analysis to determine and visualize several important and distinct types of $\mathrm{O}_{3}$ diurnal patterns that may exist in Shah Alam and Banting was conducted using the Principal Component Analysis (PCA). Visualizing $\mathrm{O}_{3}$ dispersion and pattern of outlying $\mathrm{O}_{3}$ concentrations namely $\mathrm{O}_{3}$ outliers was done using box plot and Principal Component (PC) score plot. In this study, $\mathrm{O}_{3}$ outliers with high concentration levels were treated as concentration levels that were caused by an abnormal event and could represent air quality degradation. This decision is supported by the studies of several authors [15-16]. Other than that, visualization analytics such as line chart, bar chart and spider web diagram were used to visually assess the temporal pattern of 
potential $\mathrm{O}_{3}$ severitybased on $\mathrm{O}_{3}$ exceedances. Exceedances are defined as the amount by which Ozone concentration level exceeds the MAQG standard of $0.01 \mathrm{ppm}$ (the 1 hour averaging time). This standard is designed to protect the public from adverse health effects that occur after being exposed to the pollutant [17].

Principal component analysis (PCA) is a statistical exploratory multivariate data analysis technique with a mathematical algorithm that reduces the dimensionality of the data while retaining most of the variation in the data set [18]. In this study, the PCA is used to identify several important modes of variation that explained the total variation in $\mathrm{O}_{3}$ process system at each study location. In PCA, eigenvalues and factor loading statistics play important role to describe the variation contributed by each component. The eigenvalue is used to describe the percent of variation in the data explained by each of the component obtained, while factor loading is used to identify the contribution pattern of each variable (hour) towards the response (i.e. $\mathrm{O}_{3}$ ). Plots between the scores of the PCA were used to visualize the dispersion pattern of $\mathrm{O}_{3}$ concentration. Plots of PCA factor loading will also be used to identify several distinct patterns of $\mathrm{O}_{3}$ diurnal variations. To conduct PCA in this study analysis, variable hours within the day period are considered as multivariate variables.

\section{RESULTS AND DISCUSSION}

In this section, results of the study analyses are discussed. It begins by understanding the pattern of the hourly variations that describe the day-to-day $\mathrm{O}_{3}$ variations at the study locations and then followed by visualizing and investigating the temporal and spatial patterns of the $\mathrm{O}_{3}$ outliers and exceedances.

\subsection{Diurnal Levels of $\mathrm{O}_{3}$ Concentration}

Multiple box plot analysis is given in the following Fig. 2 visually describes the distribution of diurnal $\mathrm{O}_{3}$ concentration level including the hourly median, lower quantile and upper quantile and outliers. The figure simultaneously displays information on the average and abnormal hourly $\mathrm{O}_{3}$ behaviorover a day period between Shah Alam and Banting. The average level is shown by the median value, while points above the upper whisker of the box plot indicate the outliers. 

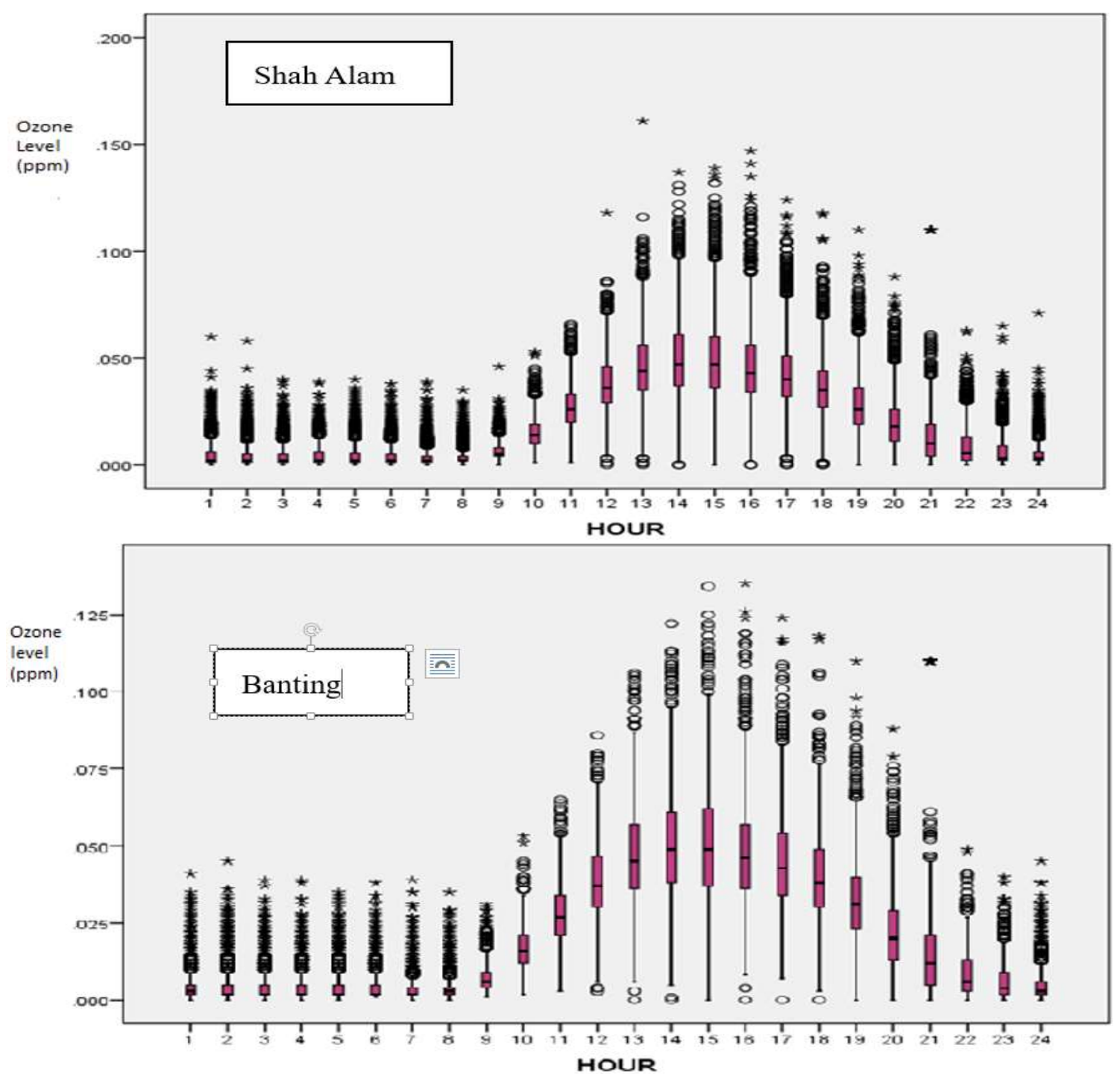

Fig.2. Multiple box plot of hourly $\mathrm{O}_{3}$

It is also showed that Banting has a slightly higher average $\mathrm{O}_{3}$ as well as more abnormal concentration levels compared to Shah Alam. The concentrations are low in the night and morning hours before sunset but high during the day after sunset. Higher pattern of dispersion points was shown during the afternoon hours and was seen critical around 2:00-3:00 p.m. Hence, it indicates the most potential time that $\mathrm{O}_{3}$ pollution can have the most severe impact on a human's health. The figure has also provided insight that the daily $\mathrm{O}_{3}$ problem in Banting is more severe than in Shah Alam.

\subsection{Pattern of Day-to-Day $\mathrm{O}_{3}$ Variations}

PCA has been conducted with the aim to observe several important patterns or modes of diurnal variations (i.e. hourly variations of $\mathrm{O}_{3}$ level within the 24-hour period) that exist in 
Shah Alam and Banting. The determination on how many number of mode was based on the analysis of the scree plot given in Fig. 3.
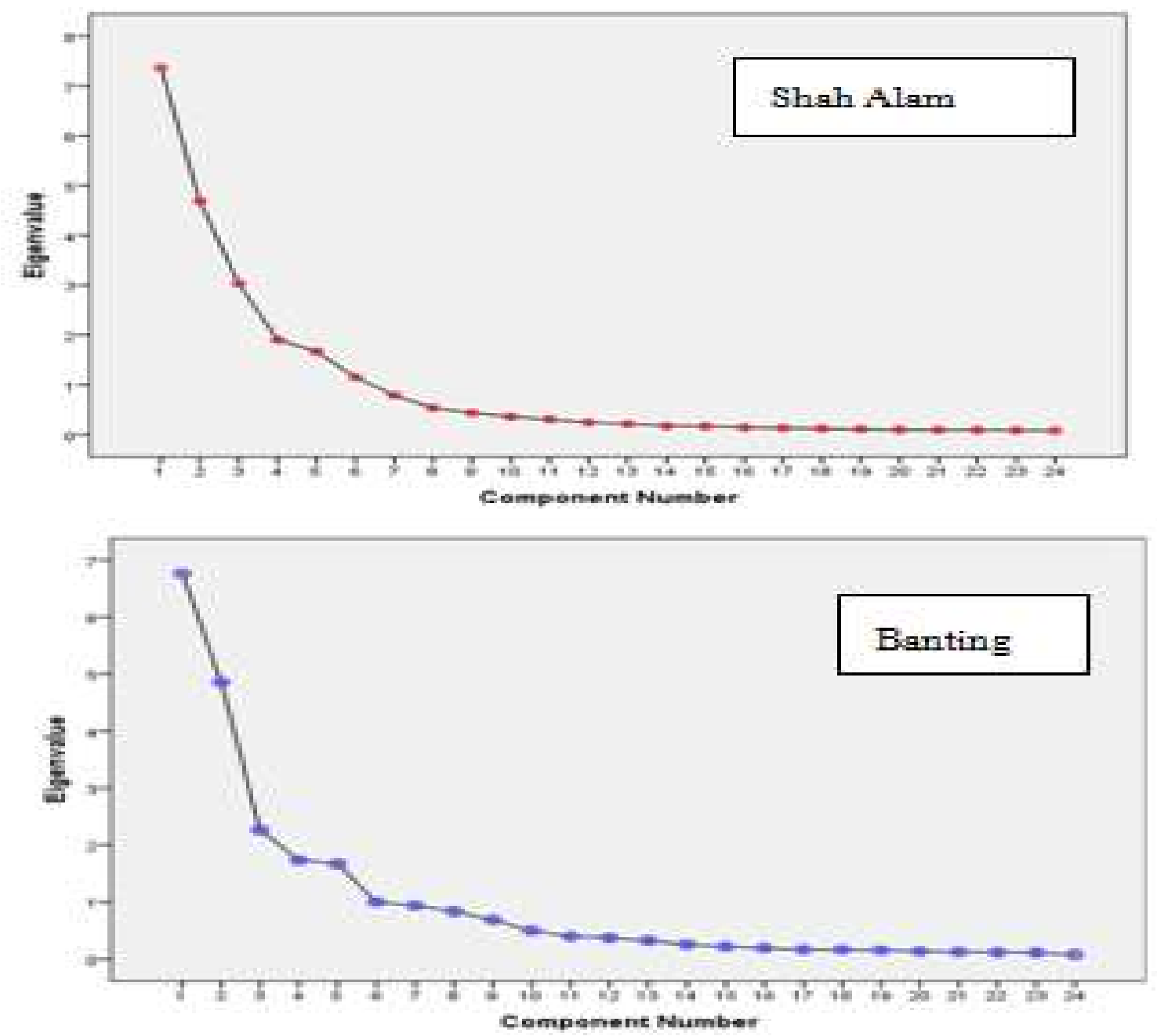

Fig.3. Scree plot to determine the number of retained component for PCA

A scree plot displays the eigenvalues associated with a component in descending order versus the number of the component. The scree plot is used to visually assess which components to explain most of the variability in the data and how many will be sufficient enough to be retained to explain the total variations in the data. This is indicated by the components above the reflection point. Based on Fig. 3, it is shown that there are six and five important patterns of variation to describe the hourly $\mathrm{O}_{3}$ levels in Shah Alam and Banting respectively.

With six components, eigenvalues accounted for $82.6 \%$ of variations in Shah Alam and with five components, eigenvalues accounted for $72 \%$ in Banting. The principal components (PC) retained are in the order: the first component $(\mathrm{PC} 1)$ contributed the most to the total variation, 
then followed by the second component (PC2) and so on. The components are independent and each component has its own pattern of contribution hours to the variation. To visualize the pattern, line charts were constructed using the PCA [26-31] factor loading as depicted in Fig. 4.
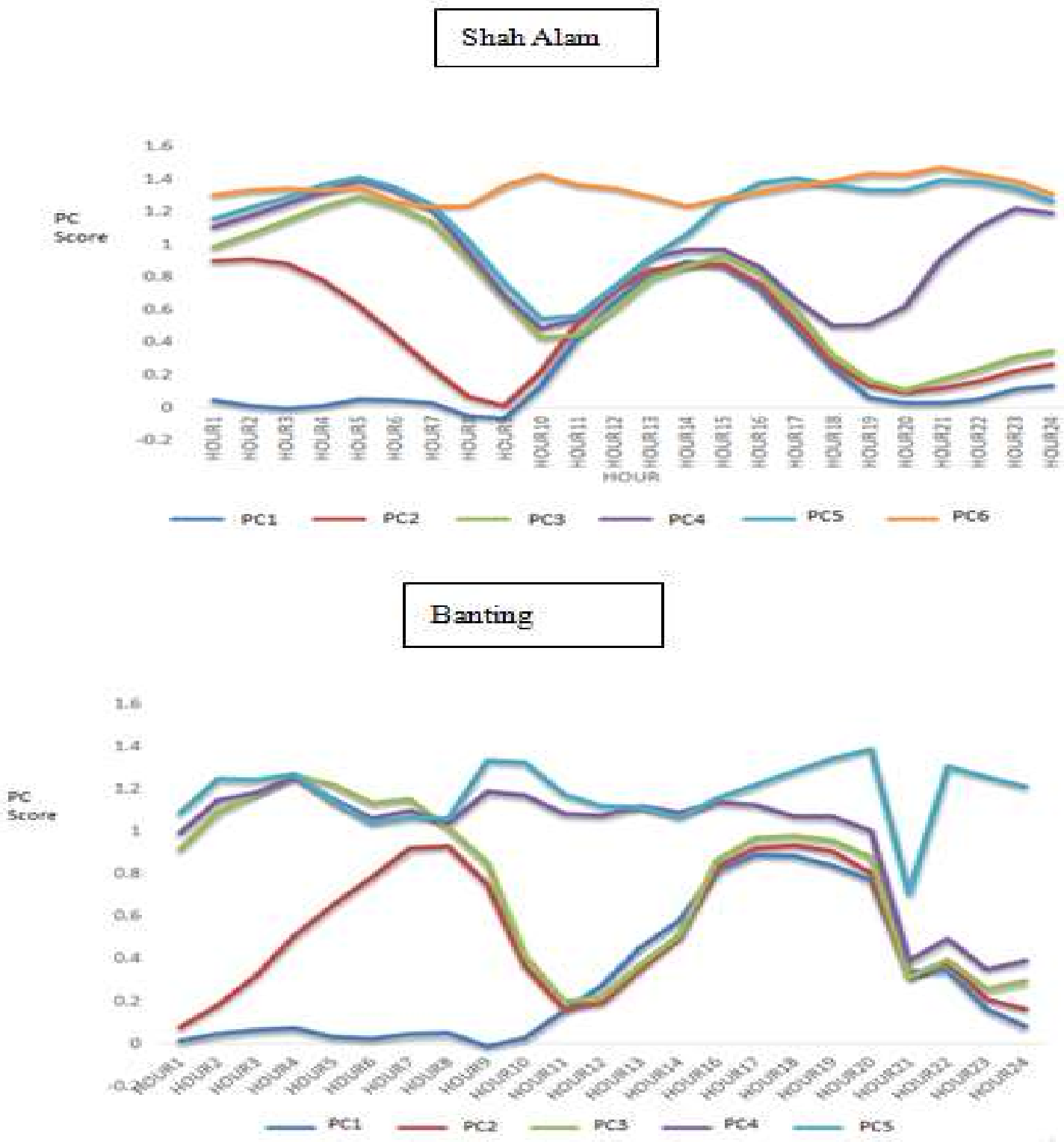

Fig.4. PC of important diurnal variations

Fig.4 shows six different patterns of component variation that exist in Shah Alam, while five component patterns in Banting. This figure helps to visualize the hours that contribute most to the $\mathrm{O}_{3}$ variation within a day period between the locations. The most important component variation for the two locations represented by $\mathrm{PC1}$ shows a similar unimodal pattern. 
However, the peak of the PC1 variation in Shah Alam occurred around 2:00-3:00 p.m and around 5:00-6:00 p.m in Banting. The pattern of strong contribution hours during the daylight hours given by PC1 coincides with the period of hours where photochemical activity takes place. Supported by [19], industrial emission has been identified as the most significant contributor to photochemical activity.

The second principal component (PC2) in Fig. 4 also exhibits a similar bimodal pattern but again, the peaks differ. The first peak in Shah Alam occurred in the early morning hours after midnight, while the first peak occurred after sunrise in Banting. The second peak still occurred at the same time as in PC1 for both locations. The third, fourth and fifth PC (PC3, PC4 and PC5) behaved in different distinct patterns between the two locations.

Analysis to visualize the dispersion pattern of the PC scores between the most important principal components obtained was also conducted. The analysis is conducted to figure out which monsoon has more potential to experience severe $\mathrm{O}_{3}$ pollution. Again, the dispersion pattern of the component scores will be observed and assessed here. The further the distance of the score from the group indicates the higher the influence of $\mathrm{O}_{3}$ to air quality degradation. As mentioned by [18], the PC score plot is an alternative method to observe outlying pattern in the data set. For this study, the scope is to only consider the two most important components that describe the total variation of $\mathrm{O}_{3}$ concentration level (i.e. $\mathrm{PC} 1$ and $\mathrm{PC} 2$ ).

Fig. 5 shows that, PC1 and PC2 in Shah Alam are more dispersed compared to Banting. The highest variation falls within the Northeast monsoon, while the lowest variation falls within the Southeast monsoon at both locations. The most outlying score belongs to the variation that is explained by PC2 at both locations. Stronger overlapping pattern of multiple coloured points towards the y-axis side is also observed. Thus, these results have provided evidence that the $\mathrm{O}_{3}$ variation, as explained by $\mathrm{PC} 1$ is more dominant in Shah Alam and Banting compared to PC2. Upon visualization, the results have shown that PC1 and PC2 variations are dominant during the Northeast monsoon and least dominant during the Southeast monsoon and the most extreme $\mathrm{O}_{3}$ variation is contributed by $\mathrm{PC} 2$. 

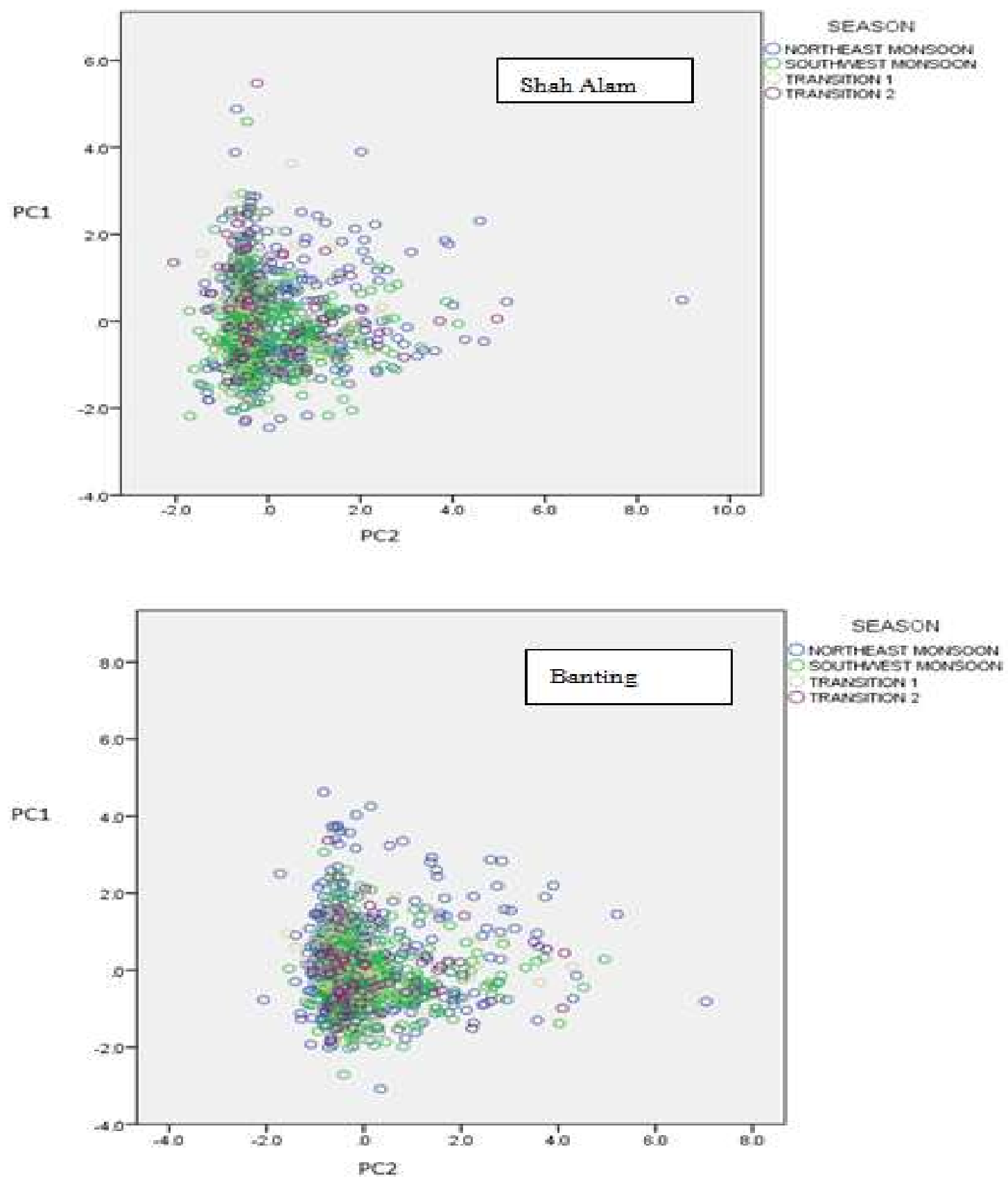

Fig.5. Dispersion pattern of PC1 and PC2 scores according to seasons

\subsection{Pattern of Ozone Exceedances}

The following results of the analysis conducted help to visualize the temporal pattern of the $\mathrm{O}_{3}$ pollution exceedances. The results provide information on when and where $\mathrm{O}_{3}$ pollution would potentially be severe. As shown in Fig. 6, frequency of exceedances in Banting is twice 
in number in 2012, 2013 and 2014 compared to Shah Alam. The results showed that $\mathrm{O}_{3}$ exceedances are increasing year by year.

The results have indicated that Banting is expected to experience a more severe $\mathrm{O}_{3}$ pollution compared to Shah Alam. This information has become a new finding. Before this, a study by [6] has shown that in the Selangor state, Cheras and Shah Alam have a very high number of hours and days of noncompliance with the standard. They also found that the $\mathrm{O}_{3}$ exceedances in Shah Alam and Cheras do not depend on geographical proximity, but the primary sources such as mobile and industrial emissions may contribute to stronger variations in $\mathrm{O}_{3}$ exceedances than the regional transport of $\mathrm{O}_{3}$.

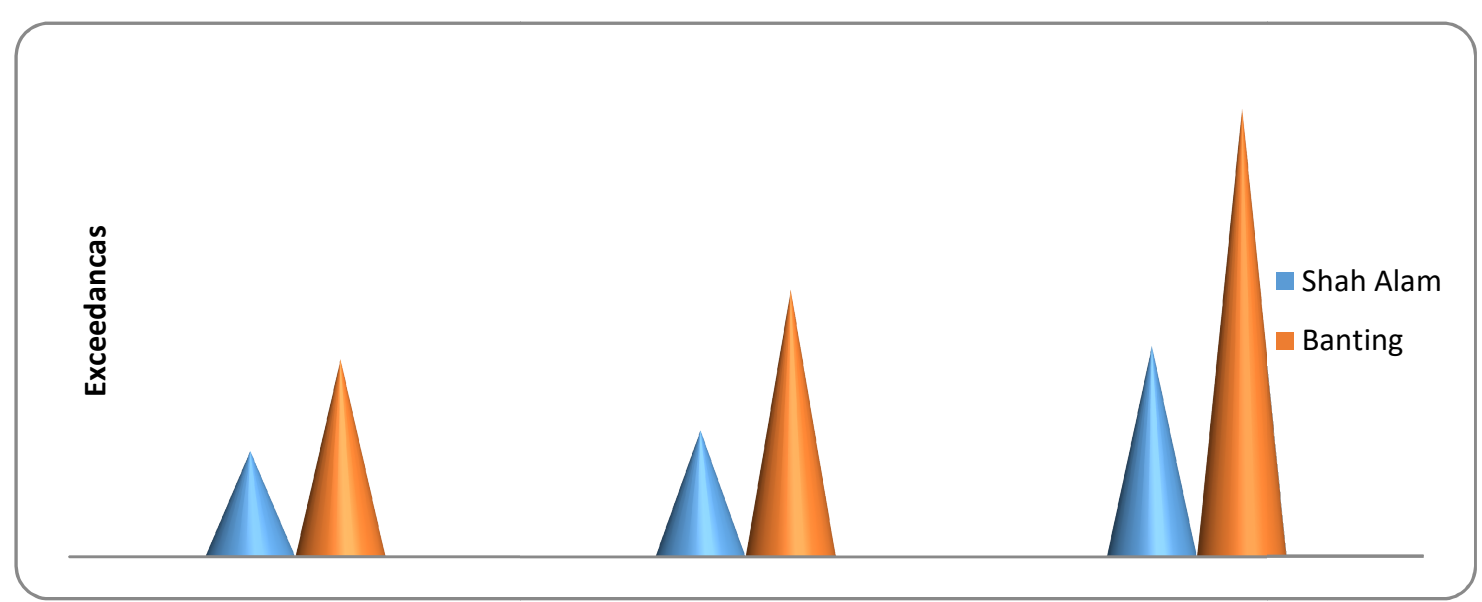

Fig.6. Frequency of ozone exceedancesby annual basis

Fig. 7 shows that higher exceedance occurrences were not observed on the weekend (Saturday and Sunday). Highest exceedances occurred on Tuesday and lowest on Sunday. The results provide evidence that Shah Alam and Banting experience the $\mathrm{O}_{3}$ "Weekend effect". It is a phenomenon where the $\mathrm{O}_{3}$ level is higher during the weekdays compared to the weekends. The phenomenon often occurs in many urban areas. Many studies worldwide have conducted more comprehensive studies on $\mathrm{O}_{3}$ weekend effect to provide ambient experimental evidence of $\mathrm{O}_{3}$ formation sources and destruction at a particular location [20-21] as well as to provide deep insights in controlling photochemical pollution [22]. The main causes of weekend effect phenomena were identified worldwide due to different reductions for NOx and VOC [23]. Over the weekend, normally there will be less number of vehicles and industrial activity in Banting and Shah Alam, resulted into less amount of NOx. Thus, this could be the reason of less active photochemical production of $\mathrm{O}_{3}$ during the weekend at these two locations. 


\section{Shah Alam}

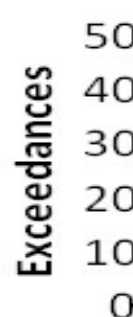

Banting

Fig.7. Ozone exceedances by day of week basis

The spider web diagram depicted in Fig. 8 shows the dispersion pattern of $\mathrm{O}_{3}$ excedances according to months in a year. It is showed that March is the most affected month, followed by April, February, October, June, December and September while no exceedances was recorded in July, August and January in Shah Alam. For Banting, the results also show that the most affected month is March. All months in the year also recorded $\mathrm{O}_{3}$ pollution. Obviously, on a monthly basis, Shah Alam and Banting have different patterns of $\mathrm{O}_{3}$ pollution. The differences are very much related with the differences in the weather and meteorological variations. Reported in [24], March is among the month that has recorded less number of rainfall and lower average precipitation levels.
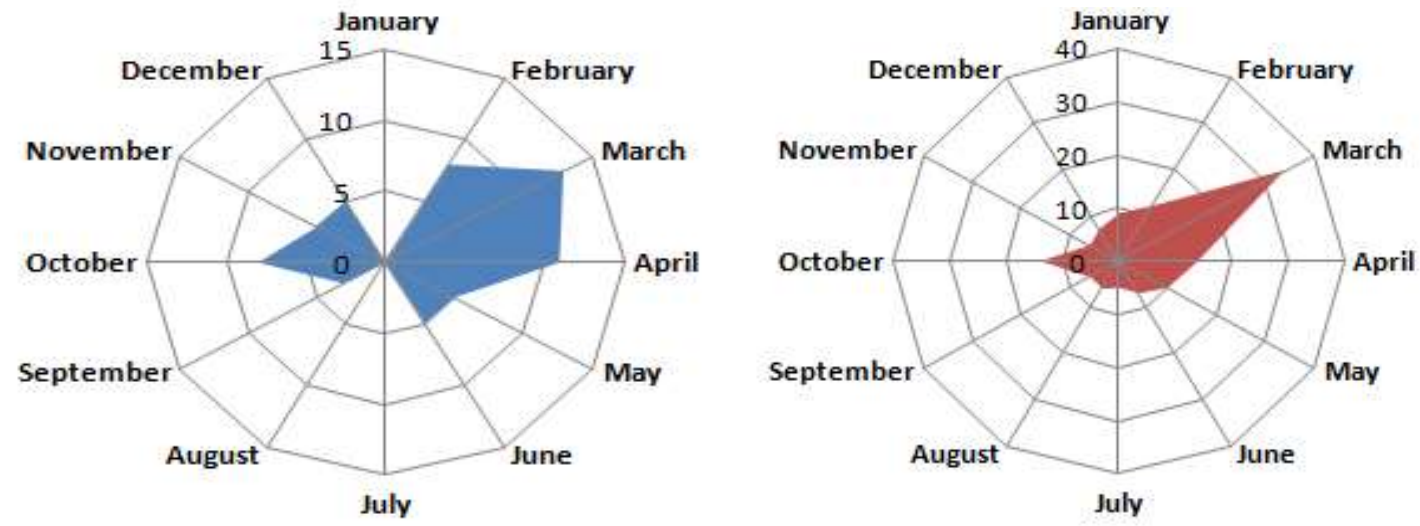

Fig.8. Ozone exceedances by monthly basis in Shah Alam (blue) and Banting (red)

\section{CONCLUSION}

The use of data visualization in research analysis can lead to a better understanding of 
information that could be revealed from massive raw data. The information can provide insights for possible new type of problems or business that may have not been addressed before.

In this study, data visualization approach was used to provide insights on the potential occurrence of severe $\mathrm{O}_{3}$ pollution between urban (Shah Alam) and sub-urban (Banting) locations situated in the state of Selangor in Peninsular Malaysia by observing the behaviour of $\mathrm{O}_{3}$ concentration levels, outliers and exceedances. To achieve the study objectives, the Principal Component Analysis and various visualization analytics were employed. It is found that data visualization approach used in this study helps to assess the spatial temporal trend of $\mathrm{O}_{3}$ pollution occurrences, thus provides meaningful insights on when and where the $\mathrm{O}_{3}$ pollution would become more severe.

The study results have shown that at both locations, $\mathrm{O}_{3}$ pollution is expected to increase year by year. More $\mathrm{O}_{3}$ pollutions occur during the Northeast monsoon season that falls in the month of March. By diurnal basis, $\mathrm{O}_{3}$ pollution is shown to be severe during the daytime around 3:00 p.m in the evening. It is also shown that both locations have experienced the $\mathrm{O}_{3}$ weekend effect. Finally, the study has provided strong insights that Banting might experience a higher potential of $\mathrm{O}_{3}$ pollution severity compared to Shah Alam.

The study results and findings also provide a strong basis for Malaysian researcher to conduct a further detail and comprehensive study involving emission inventories, power plant plume emissions and assessment of meteorological parameters such as solar radiation intensity and cloud cover as well as health related impact of $\mathrm{O}_{3}$. Statistical model used for prediction of where and when highest $\mathrm{O}_{3}$ pollution could occur need to be considered and designed. A hybrid technique with the combination of neural network model, regression quantile and spatial analysis such as various krigging techniques can be proposed. The results also suggest the needs to increase mitigation measures. The measures could be put forward on various issues and factors such as revising the standards and deregulating of emission and sources from industry and vehicles, managing efficiency of transportation usage, mode of transport and transport policies, establishing an efficient system in dealing with complaints with regards to air pollution, controlling traffic congestions by improving design and quality of 
road and junctions as well as adopting technological innovation and advancement for air pollution control.

\section{ACKNOWLEDGEMENTS}

The authors would like to thank the Department of Environment Malaysia for providing the data. The work is supported by the UiTM's Research University Grant [600IRMI/DANA5/3/LESTARI (0124/2016)].

\section{REFERENCES}

[1] Felzer B S, Cronin T, Reilly J, Melillo J, Wang X. Impacts of ozone on trees and crops. ComptesRendusGeoscience, 2007, 339(11):784-798

[2] Sunyer J, Basagana X, Belmonte J, Anto J M. Effect of nitrogen dioxide and ozone on the risk of dying in patients with severe asthma. Thorax, 2002, 57(8):687-693

[3] Selin N E, Reilly J, Paltser S, Nam K M, Prinn R, Wu S. Global health and economic impacts of future pollution. Environmental Research Letters, 2009, 4(4):1-9

[4] Latif M T, Huey L S, Juneng L. Variations of surface ozone concentration across Klang valley Malaysia. Atmospheric Environment, 2012, 61:434-445

[5] Tan K C, Lim H S, Jafri M Z M. Analysis of total column ozone in Peninsular Malaysia retrieved from SCIAMACHY. Atmospheric Pollution Research, 2014, 5(1):42-51

[6] Ahamad F, Latif M T, Tang R, Juneng L, Dominick D, Juahir H. Variation of surface ozone exceedances around Klang Valley Malaysia. Atmospheric Environment, 2014, 139:116-127

[7] Awang N R, Elbayoumi M, Ramli N A, Yahaya A S. Diurnal variations of ground level ozone in three port cities in Malaysia. Air Quality and Health, 2016, 9(1):25-39

[8] Latif M T, Domicik D, Ahamad F, Ahamad N S, Khan M F, Juneng L, Xiang C J, Nadzir M S M, Robinson A D, Ismail M, Mead M I, Harris N R P. Seasonal and long term variations of surface ozone concentration in Malaysia Borneo. Atmospheric Environment, 2016, $573: 494-504$ 
[9] Ramli N A, Ghazali N A, Yahaya A S. Diurnal fluctuations of Ozone concentrations and its precursors and prediction of Ozone. Journal of Environmental Management, 2010, 11(2):57-69

[10] Ware C. Information visualization, perception and design. San Francisco: Elsevier, 2012

[11] Cukier K. Data, data everywhere: A special report in managing information. London: The Economist, 2010

[12] Silva S, Santos B S, Madeira J. Using color in visualization: A survey. Computer and Graphics, 2011, 35(2):320-333

[13] Orland B. Data visualization techniques in environmental management: A workshop. Landscape and Urban Planning, 1992, 21(4):237-239

[14] Daniel T C. Data visualization from decision support in environmental management. Landscape and Urban Planning, 1992, 21(4):261-263

[15] Shaadan N, Deni S M, Jemain A A. Anomaly detection and assessment of PM10 functional data at several locations in the Klang valley, Malaysia. Atmospheric Pollution Research, 2015, 6(2):365-375

[16] Anandharajan T R V, Vignajeth K K, Hariharan G A, Jijendiran R. Identification of outliers in pollution concentration levels using anomaly detection. In IEEE International Conference on Computational Techniques in Information and Communication Technologies, 2016, pp. 433-438

[17] Department of Environment (DOE) Malaysia. Malaysia 2010 report (water pollution management) outcome indicators. Putrajaya: DOE, 2010

[18] Jolliffe I. T. Principle component analysis. New York: Springer, 2002

[19] Chang S C, Lee C T. Evaluation of the temporal variations of air quality in Taipei City, Taiwan from 1994 to 2003. Journal of Environmental Management, 2008, 86(4):627-635

[20] Seguel R J, Morales R G E, Leiva G M A. Ozone weekend effect in Santiago Chile. Environmental Pollution, 2012, 162:72-79

[21] Wolff G T. The vanishing Ozone weekday/weekend effect. Journal of Air Waste Management Association, 2013, 63(3):292-299 
[22] Wang Y H, Hu B, Ji D S, Liu Z R, Tang G Q, Xin J Y, Zhang H X, Song T, Wang L L, Gao W K, Wang X K, Wang Y S. Ozone weekend effects in Beijing-Tianjin-Hebei metropolitan area, China. Atmospheric Chemistry Physics, 2014, 14(5):2419-2429

[23] Debaje S B, Kakade A D. Weekend ozone effect over rural and urban site in India. Aerosol and Air Quality Research, 2006, 6(3):322-333

[24] Malaysia Meteorological Department (MMD). Monthly rainfall review.Selangor: MMD, 2017

[25] Mustafa M, Abdul Kader S Z S, Sufian A. Coping with climate change through air pollution control: Some legal initiatives from Malaysia. In International Conference on Environment, Energy and Biotechnology, 2012, pp. 101-105

[26] Saudi A S, Kamarudin M K, Ridzuan I S, Ishak R, Azid A, Rizman Z I. Flood risk index pattern assessment: Case study in Langat river basin. Journal of Fundamental and Applied Sciences, 2017, 9(2S):12-27

[27] Kamaruzzaman A, Saudi A S, Azid A, Balakrishnan A, Abu I F, Amin N A, Rizman Z I. assessment on air quality pattern: A case study in Putrajaya, Malaysia. Journal of Fundamental and Applied Sciences, 2017, 9(4S):789-800

[28] Hanapiah S M, Saudi A S, Rizman Z I. Assessment on pattern of urban air quality by using chemometric technique: A case study in Kota Kinabalu, Sabah. Journal of Fundamental and Applied Sciences, 2017, 9(4S):861-870

[29] Saudi A S, Ridzuan I S, Balakrishnan A, Azid A, Shukor D M, Rizman Z I. New flood risk index in tropical area generated by using SPC technique. Journal of Fundamental and Applied Sciences, 2017, 9(4S):828-850

[30] Shafii N Z, Saudi A S, Mahmud M, Rizman Z I. Spatial assessment on ambient air quality status: A case study in Klang, Selangor. Journal of Fundamental and Applied Sciences, 2017, 9(4S):964-977

[31] Zakaria U A, Saudi A S, Abu I F, Azid A, Balakrishnan A, Amin N A, Rizman Z I. The assessment of ambient air pollution pattern in Shah Alam, Selangor, Malaysia. Journal of Fundamental and Applied Sciences, 2017, 9(4S):772-788 
How to cite this article:

Shaadan N, Nazeri L N, Jalani M F M, Rahman N F A A and Roslan R R. Data Visualization of Temporal Ozone Pollution between Urban and Sub-urban Locations in Selangor Malaysia. J. Fundam. Appl. Sci., 2017, 9(6S), 490-507. 